\title{
LIPOPHILICITY OF AMPHOTERIC AND ZWITTERIONIC COMPOUNDS: A COMPARATIVE STUDY OF DETERMINATION METHODS
}

Clara Ràfols*, Xavier Subirats, Javier Rubio, Martí Rosés, Elisabeth Bosch

Departament de Química Analítica and Institut de Biomedicina (IBUB), Universitat de

Barcelona, Martí i Franquès 1-11, E-08028 Barcelona, Spain

*Corresponding author

Dr. Clara Ràfols

Phone: (+34) 934034 874, Fax: (+34) 934021 233, E-mail: crafols@ ub.edu

Dr. Xavier Subirats

Phone: (+34) 934039 119, Fax: (+34) 934021 233, E-mail: xavier.subirats@ub.edu

Mr. Javier Rubio

Present address: $\quad$ Massó Analítica, S.A.

Montsià 4, 08820 El Prat de Llobregat, Spain

Phone: (+34) 932859 797, Fax: (+34) 932198165

E-mail: jr@masso.com

Prof. Martí Rosés

Phone: (+34) 934039 275, Fax: (+34) 934021 233, E-mail: marti.roses@ub.edu

Prof. Elisabeth Bosch

Phone: (+34) 934021 284, Fax: (+34) 934021 233, E-mail: e.bosch@ub.edu 


\begin{abstract}
Common drugs intended for action in plasma (antibacterials, antiallergics, diuretics...) often display both acidic and basic behavior, and some of these amphoteric compounds can appear as zwitterions. In such cases, accurate profiling of lipophilicity vs. $\mathrm{pH}$, which plays a fundamental role in drug pharmacokinetics, might be complex. In the present work two common lipophilicity estimation methods based on the drug distribution between 1-octanol and aqueous buffer i.e. phase equilibration (shake-flask) and two-phase titration (potentiometry), were compared with a high-throughput lipophilicity index, the Chromatographic Hydrophobicity Index (CHI). The results were also compared with $\log D_{\mathrm{o} / \mathrm{w}}$ pH-profiles calculated by different algorithms from ACD/Labs. Accurate and similar results were obtained for both octanol-water approaches but, due to the lower determination times and the absence of different ion-pairing buffers, potentiometry was shown to be the most convenient method. $\mathrm{CHI}$ vs. $\mathrm{pH}$ profiles provide rapid and efficient information, which is very convenient for lipophilicity screening purposes, but may differ slightly from shake-flask and potentiometric results.
\end{abstract}

\title{
Keywords
}

Lipophilicity, ampholyte, zwitterion, shake-flask, potentiometry, chromatographic hydrophobicity index (CHI).

\section{Abbreviations}

CHI: chromatographic hydrophobicity index 


\section{Introduction}

Most compounds of pharmaceutical interest are weak acids or bases. In such cases, changes in the $\mathrm{pH}$ of the medium (for instance along the gastrointestinal tract) influence the ionization state of the molecule and consequently its solubility in aqueous solution and its partition in lipidic media. Water-soluble drugs are needed in the case of oral administration and when they have to be transported through body fluids, and it is well known that ionization favors solubility. Once in solution, the drug's lipophilicity needs to be increased in order to cross lipidic membranes to reach the drug target and thus the presence of the neutral form, which is more lipophilic, is preferable. Thus, many drug molecules contain acid-base groups that help to change their degree of ionization during the uptake process. Molecules containing carboxylic or phenolic groups can be easily identified as weak acids, or in the case of aliphatic or aromatic amines, as bases. However, nitrogen atoms can lack acid-base properties (e.g., amides), or even exhibit weakly acidic behavior due to delocalization onto adjacent carbonyl groups and resonance stabilization (e.g. barbiturates) or due to the electron-withdrawing effect of sulfo groups (e.g. sulfonamides) [1]. Very often a drug presents amphiprotic characteristics, having both acidic and basic functional groups. The difference between the two $\mathrm{p} K_{\mathrm{a}}$ values has a remarkable impact on the achievable maximum mole fraction of the neutral species. For instance, as shown in Fig. 1, an amphiprotic molecule in which the acidic and basic groups are only separated by $1 \mathrm{p} K_{\mathrm{a}}$ unit can lead at a maximum mole fraction of neutral species of about $60 \%$. This fraction is increased to $83 \%$ with a $\mathrm{p} K_{\mathrm{a}}$ distance of 2 units, but will only reach a value close to unity beyond a separation of $5 \mathrm{p} K_{\mathrm{a}}$ units. This might be an issue when measuring the lipophilicity of neutral species of an amphoteric molecule. In the particular case of an acidic group that is stronger than a basic one (i.e., acidic $\mathrm{p} K_{\mathrm{a}}<$ basic $\mathrm{p} K_{\mathrm{a}}$ ) zwitterionic species appear, these being electrically neutral but bearing both a negative and a positive charge.

Prediction software can be very useful and convenient for a preliminary and rapid estimate of the lipophilicity of potential drug candidates. In general terms and for the most commonly used programs, the lipophilicity of the whole molecule is calculated from the individual contributions of separate atoms and/or structural fragments, and in some cases from intramolecular interactions [2,3]. In combination with calculated $\mathrm{p} K_{\mathrm{a}}$ values, such software provides a rough estimate of lipophilicity profiles $\left(\log D_{\mathrm{o} / \mathrm{w}} \mathrm{vs} . \mathrm{pH}\right)$, which is very useful as a starting point in experimental designs of accurate $\log P_{\mathrm{o} / \mathrm{w}}$ determination.

In the present study the lipophilicity profiles of several amphoteric drugs were determined using the classical methods based on potentiometry $[4,5]$ and shake-flask $[6,7]$ 
over a wide range of $\mathrm{pH}$ values, and the results were compared with those derived from determination methods based on the fast gradient chromatographic hydrophobicity index $\left(\mathrm{CHI}_{\mathrm{MeCN}}\right)[8,9]$, as well as the prediction made by two different approaches using the common ACD/Labs software.

\section{Material and methods}

\subsection{Reagents}

Buffers were prepared from glacial acetic acid (Baker, >99\%), phosphoric acid (Merck, $>85 \%$ ), citric acid (Fluka, >99.5\%), sodium (Baker >99.5\%) and potassium dihydrogen phosphate (Merck, >99.5\%), sodium hydrogen phosphate (Merck, >99\%), sodium or ammonium hydrogen carbonate (Fluka, >99\%), sodium carbonate (Panreac, >99.5\%), ammonia (Merck, 25\%), and anhydrous ammonium acetate (Baker, >99.5\%). When necessary, small volumes of hydrochloric acid (Merck, 25\%) or concentrated sodium hydroxide solutions (prepared from pellets, Merck, >99\%) were used for $\mathrm{pH}$ adjustment. Water was obtained from a Milli-Q plus system (Millipore, Billerica, USA) with a resistivity of $18.2 \mathrm{M} \Omega \mathrm{cm}$. The organic modifiers used in HPLC mobile phases were acetonitrile and methanol (Panreac, HPLC grade). Potassium bromide (Merck, >99\%) was used as a dead time marker. Dimethyl sulfoxide (DMSO) (Merck, >99,9\%) and $n$-octanol (Merck, >97\%) were also employed. Titrisol potassium hydroxide and hydrochloric acid from Merck were used as titrants for potentiometric measurements, and potassium chloride (Sigma, >99\%) as an electrolyte for ionic strength adjustment. The drugs (Table 1) were purchased from SigmaAldrich, all of high purity grade ( $\geq 98 \%)$.

\subsection{Instrumentation}

pH was measured using a Crison 5014 combined electrode connected to a GLP 22 potentiometer from Crison (Alella, Spain), and standard aqueous solutions ( $\mathrm{pH} 4.01,7.00$, and 9.21) were used for calibration. Partitions were equilibrated using a movil-ROD rotation shaker from Selecta (Abrera, Spain) in closed test tubes at $25^{\circ} \mathrm{C}$.

$\mathrm{p} K_{\mathrm{a}}$ and $\log P_{\mathrm{o} / \mathrm{w}}$ potentiometric measurements were carried out in a GLpKa/D-PAS automatic titrator (Sirius Analytical Instruments Ltd., Forest Row, UK).

HPLC measurements were performed on a Shimadzu (Kyoto, Japan) HPLC system consisting of two LC-10ADvp pumps, a SIL-20ACHT auto-injector, an SPD-M10AVvp diode array detector and a CTO-10ASvp oven at $25^{\circ} \mathrm{C}$ and a SCL-10Avp controller. A $5 \mu \mathrm{m}$, 
50 x 4.6 mm XTerra RP18 (Waters, Milford, EUA) column was employed. Injection volumes were between 10 and $50 \mu \mathrm{L}$, and flow rates in the range $1.0-1.5 \mathrm{~mL} \mathrm{~min}^{-1}$.

UHPLC data were recorded using a Shimadzu Nexera system with two LC-30AD pumps, a DGU-20A 5 online degasser, a SIL-30AC autosampler, a SPD-M20A diode array detector, a CTO-10ASvp oven at $25^{\circ} \mathrm{C}$, and a CBM-20Alite controller. A $1.7 \mu \mathrm{m}, 50 \times 2.1$ mm Waters (Milford, MA, USA) Acquity BEH C18, $50 \mathrm{~mm}$ x $2.1 \mathrm{~mm}$ column was employed, at a flow rate of $0.5 \mathrm{~mL} \mathrm{~min}^{-1}$ and injection volume of $0.2 \mu \mathrm{L}$.

\subsection{Determination of $\mathrm{p} K_{\mathrm{a}}$ and $\log \boldsymbol{P}_{\mathrm{o} / \mathrm{w}}$ by potentiometry}

For potentiometric $\mathrm{p} K_{\mathrm{a}}$ determination about $5 \mathrm{mg}$ of sample were dissolved in $15 \mathrm{~mL}$ of water or methanol/water mixtures containing $0.15 \mathrm{M}$ of $\mathrm{KCl}$, followed by pre-acidification or prebasification, and finally titrated with $\mathrm{KOH} 0.5 \mathrm{M}$ or $\mathrm{HCl} 0.5 \mathrm{M}$. When mixed solvents were used, extrapolated aqueous $\mathrm{p} K_{\mathrm{a}}$ values were calculated according to the Yasuda-Shedlovsky procedure. For spectrophotometric $\mathrm{p} K_{\mathrm{a}}$ determinations, a $5 \mathrm{mM}$ solution of the compound was prepared in DMSO, and $50 \mu \mathrm{L}$ of this stock solution were diluted with $250 \mu \mathrm{L}$ of $\mathrm{KH}_{2} \mathrm{PO}_{4}$ $0.015 \mathrm{M} / \mathrm{KCl} 0.15 \mathrm{M}$ and $10 \mathrm{~mL}$ of $\mathrm{KCl} 0.15 \mathrm{M}$. A blank reference titration is required [1012].

For $\log P_{\mathrm{o} / \mathrm{w}}$ determination about $5 \mathrm{mg}$ of sample were dissolved in the appropriate volume ratio of $n$-octanol (saturated with $0.15 \mathrm{M} \mathrm{KCl}$ aqueous solution) and $0.15 \mathrm{M} \mathrm{KCl}$ aqueous solution (saturated with $n$-octanol), followed by titration with $\mathrm{KOH} 0.5 \mathrm{M}$ or $\mathrm{HCl} 0.5$ $\mathrm{M}$ [4].

All measurements were performed at $25^{\circ} \mathrm{C}$, under an inert gas atmosphere, and at least three titrations were performed for each compound.

\subsection{Determination of $\log P_{\mathrm{o} / \mathrm{w}}$ by shake-flask method}

Volumes of octanol-saturated aqueous buffer and water-saturated octanol were selected according to the procedure proposed in a former study [13]. Briefly, a $10 \mathrm{mM}$ sample stock solution in DMSO was diluted in the corresponding buffer, 1:100 for regular compounds (-1.0 $\left.<\log D_{\mathrm{o} / \mathrm{w}}<3.5\right)$ and 1:40 for hydrophilic substances $\left(\log D_{\mathrm{o} / \mathrm{w}}<-1.0\right)$, followed by the addition of octanol in a volume ratio depending on the expected lipophilicity of the compound, and then the mixture was stirred for 1 hour at $25^{\circ} \mathrm{C}$. Finally, the analyte concentration was measured by HPLC in the aqueous phase before and after equilibration with octanol in the case of regular compounds, or in the octanolic phase for hydrophilic 
compounds. Thus, for a compound of regular lipophilicity $\log D_{\mathrm{o} / \mathrm{w}}$ values were calculated according to the following expression:

Regular compounds: $\log D_{\mathrm{o} / \mathrm{w}}=\log \left(\left(\frac{A_{\mathrm{st}} v_{\text {inj(w) }}}{A_{\mathrm{w}} v_{\text {inj(st) }}}-1\right) \frac{V_{\mathrm{w}}}{V_{\mathrm{o}}}\right)$

where $V_{\mathrm{w}} / V_{\mathrm{o}}$ is the volume ratio between the aqueous and the octanolic phases, $v_{\mathrm{inj}(\mathrm{w})}$ and $v_{\text {inj(st) }}$ are the injection volumes, and $A_{\mathrm{w}}$ and $A_{\mathrm{st}}$ are the chromatographic peak areas; the subscript st refers to the standard solution, i.e. the aqueous solution of the analyte of known concentration before the addition of octanol, and $w$ stands for the aqueous phase after the equilibration step with octanol. In the case of poorly lipophilic compounds:

Hydrophilic compounds: $\log D_{\mathrm{o} / \mathrm{w}}=-\log \left(\frac{A_{\mathrm{st}} v_{\mathrm{inj}(\mathrm{o})}}{A_{\mathrm{o}} v_{\mathrm{inj}(\mathrm{st})}}-\frac{V_{\mathrm{o}}}{V_{\mathrm{w}}}\right)$

where $v_{\text {inj(o) }}$ is the injection volume of the octanolic phase after equilibration.

Several aqueous buffers at ionic strength of $0.10 \mathrm{M}$ were prepared in order to cover a $\mathrm{pH}$ range between 1.90 and $11.00\left(1.90-3.10, \mathrm{H}_{3} \mathrm{PO}_{4} / \mathrm{NaH}_{2} \mathrm{PO}_{4} ; 3.75\right.$ - 5.75, $\mathrm{CH}_{3} \mathrm{COOH} / \mathrm{NaCH}_{3} \mathrm{COO} ; 6.21-8.21, \mathrm{NaH}_{2} \mathrm{PO}_{4} / \mathrm{Na}_{2} \mathrm{HPO}_{4} ; 7.00$ - 9.20, TrisHCl/Tris; 9.30 11.00, $\mathrm{NaHCO}_{3} / \mathrm{Na}_{2} \mathrm{CO}_{3}$.). These aqueous buffer solutions were saturated in octanol before use for at least 24 hours. Selected volumes of aqueous buffers and $n$-octanol are presented in Table 2 according to the expected $\log D_{\mathrm{o} / \mathrm{w}}$ value. The chromatographic elution was performed isocratically in the range between 20 and $80 \%$ of methanol, depending on the analyte, in mobile phases buffered with phosphate at $\mathrm{pH} 7.4$.

\subsection{Determination of Chromatographic Hydrophobicity Index}

CHI is a high-throughput methodology lipophilicity descriptor [8] originally intended for screening purposes, based on the retention of compounds in a reversed-phase column under a fast gradient elution. In the present work CHI measurements were carried out via the UHPLC method as described elsewhere, using acetonitrile as the organic modifier and aqueous solutions of $50 \mathrm{mM}$ ammonium acetate at the desired $\mathrm{pH}$ value (3.0, 7.4, and 11.0) [14]. In the case of neutral species, CHI values were converted into a $\log P_{\mathrm{o} / \mathrm{w}}$ lipophilicity scale by means of the following relations [15]:

$\log P_{\mathrm{o} / \mathrm{w}, \mathrm{CHI}}=0.059 C H I_{\mathrm{MeCN}}+103[H D C A-1 / T M S A]-0.15[H O M O-L U M O]-0.80$

where HDCA-1/TMSA and HOMO-LUMO are CODESSA [16] molecular descriptors accounting for hydrogen-bond acidity and polarizability, respectively (Table 3) [17]. 


\section{Results and discussion}

As mentioned in the introduction, the acidic or basic properties of a molecule, and therefore its degree of ionization, play a fundamental role in its lipophilic behavior. In fact, ionization can easily reduce the lipophilicity of a substance by about 3 or $4 \log P_{\mathrm{o} / \mathrm{w}}$ units [12]. This is just a rule of thumb, since ionic species partition into the oil phase as ion-pairs and the lipophilicity also depends on the nature and concentration of the counter-ion. Consequently, determining the lipophilicity of polyprotic compounds is very often a challenging enterprise in the drug discovery process, especially in the case of ordinary and zwitterionic ampholytes. Thus, for drugs with some structural complexity, software packages may calculate a variety of lipophilicity values depending on the differences in their algorithms [2]. Even similar computational programs offered by the same provider may show significantly different lipophilicity values for the same compound [3].

Two different predictive approaches from the ACD/Labs software, Classic and GALAS, were used in this work to calculate the $\log D_{\mathrm{o} / \mathrm{w}}$ drug profile over a wide range of $\mathrm{pH}$ [18]. Since distribution ratios depend on the partition ratios of individual species, $\log P_{\mathrm{o} / \mathrm{w}}$ values of neutral and ionized forms are first calculated by the software, and then estimated $\mathrm{p} K_{\mathrm{a}}$ values of the molecule are used to define the distribution of the species within the $\mathrm{pH}$ range. Classic $\log P_{\mathrm{o} / \mathrm{w}}$ are calculated from the contributions of atoms, structural fragments and intramolecular interactions, whereas GALAS $\log P_{\mathrm{o} / \mathrm{w}}$ are based on a training set compiled from experimental data. For $\mathrm{p} K_{\mathrm{a}}$ estimation, the Classic approach involves Hammettype equations and electronic substituent constants, whereas the GALAS procedure is based on a database of ionization centers and interaction constants of ionized groups to neighboring ionization centers.

As shown in Fig. 2, $\mathrm{p} K_{\mathrm{a}}$ values obtained by both approaches were very similar (inflection points in calculated $\log D_{\mathrm{o} / \mathrm{w}} \mathrm{vs}$. $\mathrm{pH}$ curves), but this was not the case for $\log P_{\mathrm{o} / \mathrm{w}}$ values. For instance, there was an almost constant $\log D_{\mathrm{o} / \mathrm{w}}$ shift of more than one unit along the whole $\mathrm{pH}$ range for benazepril and ciprofloxacin, and this distance increased to over $2 \log$ $D_{\mathrm{o} / \mathrm{w}}$ units for telmisartan. On the other hand, the $\log P_{\mathrm{o} / \mathrm{w}}$ of neutral molecules was comparable, whereas this was not the case for ionized species such as esomeprazole, mebendazole and sulfamethoxazole. In all cases, the extent of the plateau of maximum lipophilicity, corresponding to the $\log P_{\mathrm{o} / \mathrm{w}}$ of the neutral species, depended on the difference in $\mathrm{p} K_{\mathrm{a}}$ between the acidic and the basic groups. For esomeprazole, haloperidol, mebendazole, 
pantoprazole, and sulfamethoxazole, all of them with $\Delta \mathrm{p} K_{\mathrm{a}} \geq 4$, the plateau was clearly visible, whereas for substances with $\Delta \mathrm{p} K_{\mathrm{a}} \leq 2$ it was simply reduced to an apex.

Thus, computer programs provide an estimation of the lipophilicity profile of acidbase compounds, but the proper establishment of this profile requires experimental determination. There are several measurement methods and the most common (shake-flask, potentiometry, chromatography through $\mathrm{CHI}$ ) were used in this work, with the results obtained for a selected group of amphoteric and zwitterionic compounds being compared between methods and with computer estimations.

As shown earlier, the $\log D_{\mathrm{o} / \mathrm{w}}$ profile of a polyprotic compound depends on the $\mathrm{pH}$ of the medium, the $\mathrm{p} K_{\mathrm{a}}$ of the successive dissociation steps, and the partition ratios $\left(\log P_{\mathrm{o} / \mathrm{w}}\right.$ values) of individual species between the aqueous and the octanolic phases, usually expressed by:

$$
\log D_{\mathrm{o} / \mathrm{w}}=\log \frac{P_{\mathrm{H}_{n} \mathrm{X}^{z}}+\sum_{i=1}^{n} P_{\mathrm{H}_{n-i} \mathrm{X}^{z-i}} \cdot 10^{i \mathrm{pH}-\sum_{j=1}^{i} \mathrm{p} K_{\mathrm{aj}}^{\prime}}}{1+\sum_{i=1}^{n} 10^{i \mathrm{pH}-\sum_{j=1}^{i} \mathrm{p} K_{\mathrm{aj}}^{\prime}}}
$$

where $\mathrm{H}_{n} \mathrm{X}^{\mathrm{z}}$ refers to the fully protonated species (neutral form of a weak acid, or cationic species of a weak base) since $n$ is the total number of ionizable groups and $z$ is the maximum number of positive charges ( $z=0$ for acids, $z \geq+1$ for bases), and $\mathrm{p} K_{\mathrm{a} j}^{\prime}$ stands for the mixed $\mathrm{p} K_{\mathrm{a}}$ of the subscript species (i.e. the activity of the proton measured by the glass electrode, but the concentration of the acid/base species). In Eq. (4) ionic species are considered to partition into the octanolic phase as ion-pairs, normally taking any of the buffer ions as a counter-ion. At this point two issues should be taken into consideration: 1) the $\log P_{\mathrm{o} / \mathrm{w}}$ values of ion-pairs depend on the nature and concentration of the counter-ion [12]; and 2) $\mathrm{p} K_{\mathrm{a} j}^{\prime}$ values obtained from fittings to Eq. (4) depend on the thermodynamic $\mathrm{p} K_{\mathrm{a}}$ and the ionic activity coefficients, which in turn are influenced by the ionic strength of the medium.

The acidity constants from shake-flask measurements fitted to Eq. (4) and those determined by potentiometry are presented in Table 4 . It must be pointed out that the latter are reported on a concentration scale $\left(\mathrm{p} K_{\mathrm{a} j}^{\prime \prime}\right.$, i.e. the acidity constant expressed in terms of concentrations, including that of hydrogen ions, instead of activities, and at different ionic strengths: $0.10 \mathrm{M}$ for shake-flask and $0.15 \mathrm{M}$ for potentiometry). Both sets of values showed generally good consistency (most differences were less than $0.5 \mathrm{p} K_{\mathrm{a}}$ units), indicating that, in 
most cases, side interactions with the buffer components in the $\mathrm{pH}$ range considered for the shake-flask fittings are not significant.

As shown in Table 5, shake-flask and potentiometric methods led to very similar log $P_{\mathrm{o} / \mathrm{w}}$ values in most instances. Consequently, as the acidity constants were similar, the $\log D_{\mathrm{o} / \mathrm{w}}$ profiles shown in Fig. 2 matched quite nicely. Slight differences were observed for the zwitterionic telmisartan and the positively charged ciprofloxacin species, but they are quite large for labetalol and haloperidol below $\mathrm{pH} 3.5$. In fact, $\log D_{\mathrm{o} / \mathrm{w}}$ values obtained by the shake-flask in these acidic conditions were not included in the fittings of Eq. (4). Differences for ionized species might be attributed to diverse ion pairing effects between the buffering agent in the case of the shake-flask and the potassium chloride used for the potentiometric method. The lowest $\mathrm{p} K_{\mathrm{a}}$ of haloperidol corresponded to the weak tertiary amine, and had a value of 8.48. There was no apparent reason for the decrease in the shake-flask lipophilicity below $\mathrm{pH} 3.5$, except for the presence of phosphoric acid and dihydrogen phosphate as buffering species (Table 2); above $\mathrm{pH} 3.75$, acetic acid and acetate were used instead.. However, the particular reasons for this behavior remain unclear and require further investigation. For the ciprofloxacin there was a slight difference between the shake-flask and the potentiometric profiles in the acidic region corresponding to the cationic acid species. In fact, the $\mathrm{p} K_{\mathrm{a} 1}^{\prime}$ value fitted from shake-flask data (Table 4), which exhibited a relatively high fitting error, was about 2 units lower in relation to the $\mathrm{p} K_{\mathrm{a}}$ determined in the present work by the reference potentiometric method and the values found in the literature [19]. Thus, high $\mathrm{p} K_{\mathrm{a} 1}^{\prime}$ difference was likely due to the very low $\log P_{\mathrm{o} / \mathrm{w}}$ values of both neutral and cationic species of ciprofloxacin and the small difference between them, which led to high fitting errors. Measured $\log D_{\mathrm{o} / \mathrm{w}}$ values for this fluoroquinolone in the region buffered by acetic acid/acetate were slightly higher than expected, suggesting some kind of analyte-buffer interaction.

In summary, assuming that consistent lipophilicity values are obtained by both the shake-flask and the potentiometric methods, the latter seems to be more convenient because of the shorter determination times. In addition, potentiometry removes the need for the preparation of several $\mathrm{pH}$ buffers and avoids the effect of different buffer counter-ions on the lipophilicity of ionized acid-base compounds.

Similarly to Eq. (4), a CHI profile can be defined as a function of the CHI of individual species, acid-base constants, and $\mathrm{pH}$ of the medium [20]: 


$$
C H I=\frac{C H I_{\mathrm{H}_{n} \mathrm{X}^{z}}+\sum_{i=1}^{n} C H I_{\mathrm{H}_{n-i} \mathrm{X}^{z-i}} \cdot 10^{\sum_{j=1}^{i} s_{j}\left(\mathrm{pH}-\mathrm{p} K_{\mathrm{aj}}^{\prime}\right)}}{1+\sum_{i=1}^{n} 10^{\sum_{j=1}^{i} s_{j}\left(\mathrm{pH}-\mathrm{p} K_{\mathrm{aj}}^{\prime}\right)}}
$$

where $s$ is an empirical parameter accounting for the dynamics of the gradient elution [21]. The solvent change during the run implies continuous variations in the mobile phase $\mathrm{pH}$ and the analyte $\mathrm{p} K_{\mathrm{a}}$. In most cases CHI values can be rapidly obtained for neutral and ionized species, the $\mathrm{pH}$ range of applicability only being limited by the stability of the chromatographic column. Since $\mathrm{CHI}_{\mathrm{MeCN}}$ measurements are based on a fast gradient using acetonitrile as the organic modifier, $\mathrm{p} K_{\mathrm{a}}$ values of Eq. (5) are an average of the $\mathrm{p} K_{\mathrm{a}}$ values in these hydro-organic solvent mixtures and do not match the potentiometric (or shake-flask) aqueous $\mathrm{p} K_{\mathrm{a}}$ (Table 4). This is why the CHI profiles did not match the $\log D_{\mathrm{o} / \mathrm{w}}$ profiles, as shown in Fig. 2, although they showed a similar trend. In the case of mebendazole, which exhibited a difference between consecutive $\mathrm{p} K_{\mathrm{a}}$ values of 6.35 units, no significant changes were observed in $\mathrm{CHI}$ value (from 60 to 62) in the studied $\mathrm{pH}$ range. The $\mathrm{CHI}$ profile obtained for labetalol was consistent with that obtained in a previous study [20], showing that CHI values are indeed independent of the particular C18 column employed.

Although general conversion between chromatographic and $\log P_{\mathrm{o} / \mathrm{w}}$ lipophilicity scales is in principle possible [22, 23], it can only be applied to neutral compounds and requires the calculation of molecular descriptors (Eq. (3), Table 3). Even so, we applied Eq. (3) to convert the CHI to the $\log D_{\mathrm{o} / \mathrm{w}}$ scale for all obtained CHI data for a particular compound. This conversion is illustrated in Fig. 2, i.e. the obtained CHI value of the drug can be read on the righthand y-axis and the corresponding calculated $\log D_{\mathrm{o} / \mathrm{w}}$ (from Eq. 3 and the particular drug descriptor (Table 3)) on the lefthand y-axis. However as shown in Table 5, log $P_{\mathrm{o} / \mathrm{w}}$ values obtained from CHI measurements differed slightly from those measured by shakeflask and potentiometry. The main reasons may lie in the nature of the $\mathrm{CHI}$ approach, since it is an indirect method for $\log P_{\mathrm{o} / \mathrm{w}}$ determination, and in addition, for most of the zwitterionic compounds, there is the issue of the reduction of the molar fraction of neutral species when acetonitrile is added to the aqueous buffer to prepare the mobile phase. Thus, acidic groups increase their $\mathrm{p} K_{\mathrm{a}}$ values with the content of organic modifier, whereas basic groups show the opposite trend. For instance, benazepril has two functional groups with acid-base properties, a carboxylic aliphatic acid and secondary amine of aqueous $\mathrm{p} K_{\mathrm{a}}$ values of 3.35 and 5.43, respectively. Thus, in pure water, the neutral form of this compound is a zwitterion. When 
$30 \%$ of acetonitrile is added, the first $\mathrm{p} K_{\mathrm{a}}$ is expected to shift up to 3.95 and the second one to shift down to 4.96 [24], reducing the distance between $\mathrm{p} K_{\mathrm{a}}$ values from 2.1 to 1.0 units. When the percentage of acetonitrile in the hydro-organic mixture exceeds $60 \%$, the $\mathrm{p} K_{\mathrm{a}}$ variation continues until the amine becomes stronger (4.33) than the carboxylic acid (4.75), and thus the main neutral compound is no longer a zwitterion. The shorter the $\mathrm{p} K_{\mathrm{a}}$ distance, the lower the mole fraction of neutral species found in solution. Moreover, both the $\mathrm{p} K_{\mathrm{a}}$ and the $\mathrm{pH}$ of the mobile phase change with the organic modifier, which requires an accurate $\mathrm{pH}$ measurement of the mobile phase or alternatively some previous calculations in order to find the most appropriate $\mathrm{pH}$ for the aqueous buffer [24]. Therefore, even under the most favorable mobile phase $\mathrm{pH}$, it is not possible to measure the retention of the isolated neutral species, but only a mixture of neutral and ionized forms.

A second reason for the lower accuracy of chromatographic methods in relation to shake-flask and potentiometry arises from the molecular descriptors. They are always calculated from the uncharged form, even in the case of zwitterionic species, and this must affect the charge distribution and the geometry of the molecule, and consequently the accuracy of the molecular descriptors.

\section{Conclusions}

For the studied amphoteric compounds, the shake-flask and potentiometric methods led to very similar $\log D_{\mathrm{o} / \mathrm{w}} \mathrm{pH}$-profiles, and consequently to comparable $\log D_{\mathrm{o} / \mathrm{w}}$ profiles. Differences for ionized species between the two methods (e.g. haloperidol or labetalol at acidic $\mathrm{pH}$ ) might be attributed to differential ion pairing effects between the buffering agent in the case of the shake-flask and the potassium chloride required for the potentiometric method. Since the phase equilibration method is extremely time consuming and requires buffers of different nature according to their buffer capacity and working $\mathrm{pH}$, the potentiometric methods seems to be more advantageous.

Prediction software can be very useful for defining the start-up conditions for the experimental determination, since they provide a preliminary estimate of $\log D_{\mathrm{o} / \mathrm{w}}$ profiles over the whole $\mathrm{pH}$ range. However, their accuracy compared with experimental values may not be very good, and different prediction algorithms may lead to diverse results for the same compound.

The CHI methodology is very convenient for lipophilicity screening purposes, due to its rapidity and wide $\mathrm{pH}$ range of applicability, but the $\log P_{\mathrm{o} / \mathrm{w}}$ values from $\mathrm{CHI}$ 
measurements are expected to be less accurate than those obtained using the shake-flask and potentiometric methods.

\section{ACKNOWLEDGEMENTS}

This work was supported by the Ministry of Economy and Competitiveness of Spain (project CTQ2014-56253-P).

\section{CONFLICT OF INTEREST STATEMENT}

The authors declare no conflict of interest.

\section{REFERENCES}

[1] D. Cairns, Essentials of Pharmaceutical Chemistry, 4th ed., Pharmaceutical Press, London, UK, 2012.

[2] I.V. Tetko, G.I. Poda, C. Ostermann, R. Mannhold, Large-Scale Evaluation of log P Predictors: Local Corrections May Compensate Insufficient Accuracy and Need of Experimentally Testing Every Other Compound, Chem. Biodivers., 6 (2009) 1837-1844.

[3] J.M. Pallicer, M. Rosés, C. Ràfols, E. Bosch, R. Pascual, A. Port, Evaluation of $\log P_{\mathrm{o} / \mathrm{w}}$ values of drugs from some molecular structure calculation software, ADMET \& DMPK, 2 (2014) 107-114.

[4] A. Avdeef, pH-Metric log P. Part 1. Difference Plots for Determining Ion-Pair OctanolWater Partition Coefficients of Multiprotic Substances, Quant. Struct-Act. Rel., 11 (1992) 510-517.

[5] A. Avdeef, pH-metric log P. II: Refinement of partition coefficients and lonization constants of multiprotic substances, J. Pharm. Sci., 82 (1993) 183-190.

[6] OECD, Guideline for the testing of chemicals. Method 107. Partition coefficient ( $n$ octanol/water): shake flask method, 1995.

[7] EPA, Product Properties Test Guidelines. OPPTS 830.7550 Partition coefficient ( $n$ octanol/water), shake flask method, United States, 1996.

[8] K. Valkó, C. Bevan, D. Reynolds, Chromatographic Hydrophobicity Index by FastGradient RP-HPLC: A High-Throughput Alternative to $\log P / \log D$, Anal. Chem., 69 (1997) 2022-2029.

[9] M. Rosés, E. Bosch, C. Ràfols, E. Fuguet, Chromatographic hydrophobicity index (CHI), Advances in Chromatography, CRC Press, Boca Raton, FL, U.S., 2012, pp. 377-414. 
[10] A. Avdeef, J.E.A. Comer, S.J. Thomson, pH-Metric log P. 3. Glass electrode calibration in methanol-water, applied to $\mathrm{p} K_{\mathrm{a}}$ determination of water-insoluble substances, Anal. Chem., 65 (1993) 42-49.

[11] K.Y. Tam, K. Takács-Novák, Multiwavelength spectrophotometric determination of acid dissociation constants: a validation study, Anal. Chim. Acta, 434 (2001) 157-167.

[12] A. Avdeef, Absorption and Drug Development: Solubility, Permeability, and Charge State, 2nd edition, Wiley, Hoboken, NJ, US, 2012.

[13] A. Andrés, M. Rosés, C. Ràfols, E. Bosch, S. Espinosa, V. Segarra, J.M. Huerta, Setup and validation of shake-flask procedures for the determination of partition coefficients $(\log D)$ from low drug amounts, Eur. J. Pharm. Sci., 76 (2015) 181-191.

[14] J.M. Cabot, X. Subirats, E. Fuguet, M. Rosés, High throughput determination log $P_{\mathrm{o} / \mathrm{w}} / \mathrm{p} K_{\mathrm{a}} / \log D_{\mathrm{o} / \mathrm{w}}$ of drugs by combination of UHPLC and CE methods, ADMET \& DMPK, 2 (2014) 98-106.

[15] X. Subirats, M. Rosés, E. Bosch, High-throughput $\log P_{\mathrm{o} / \mathrm{w}}$ determination from UHPLC measurements: revisiting the Chromatographic Hydrophobicity Index J. Pharm. Biomed. Anal., 127 (2016) 26-31.

[16] CODESSA, CompuDrug, Bal Harbor, Florida, USA. www.compudrug.com.

[17] A.R. Katritzky, V.S. Lovanov, M. Karelson, CODESSA, Reference Manual V 2.13, Semichem and the University of Florida, 1997.

[18] ACD/Labs, Advanced Chemistry Development, Inc., Toronto, Canada. http://www.acdlabs.com/products/percepta/predictors/logd/.

[19] G.-M. Cárdenas-Youngs, J.-L. Beltrán, Dissociation Constants and Octanol-Water Partition Equilibria for Several Fluoroquinolones, J. Chem. Eng. Data, 60 (2015) 33273332.

[20] E. Fuguet, C. Ràfols, E. Bosch, M. Rosés, Chromatographic hydrophobicity index: pH profile for polyprotic compounds, J. Chromatogr. A, 1216 (2009) 7798-7805.

[21] I. Canals, K. Valkó, E. Bosch, A.P. Hill, M. Rosés, Retention of Ionizable Compounds on HPLC. 8. Influence of Mobile-Phase pH Change on the Chromatographic Retention of Acids and Bases during Gradient Elution, Analytical Chemistry, 73 (2001) 4937-4945.

[22] K. Valko, C.M. Du, C. Bevan, D.P. Reynolds, M.H. Abraham, Rapid method for the estimation of octanol/water partition coefficient $\left(\log \mathrm{P}_{\text {oct }}\right)$ from gradient RP-HPLC retention and a hydrogen bond acidity term $\left(\sum \alpha_{2}{ }^{H}\right)$, Curr. Med. Chem., 8 (2001) 11371146. 
[23] J.M. Pallicer, R. Pascual, A. Port, M. Rosés, C. Ràfols, E. Bosch, The contribution of the hydrogen bond acidity on the lipophilicity of drugs estimated from chromatographic measurements, Eur. J. Pharm. Sci., 48 (2013) 484-493.

[24] X. Subirats, M. Rosés, E. Bosch, On the Effect of Organic Solvent Composition on the $\mathrm{pH}$ of Buffered HPLC Mobile Phases and the $\mathrm{p} K_{\mathrm{a}}$ of Analytes - A Review, Sep. Purif. Rev., 36 (2007) 231-255. 


\section{TABLES}

Table 1. Studied compounds.

\section{Compound}

Benazepril

Ciprofloxacin

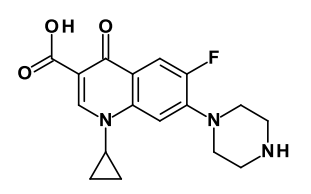

Esomeprazole

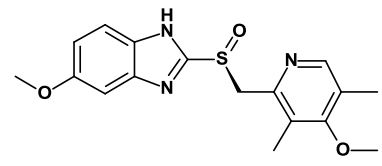

Haloperidol

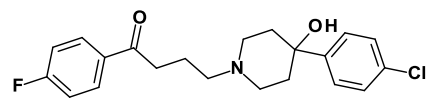

Labetalol

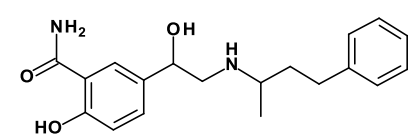

\section{Compound}

Mebendazole

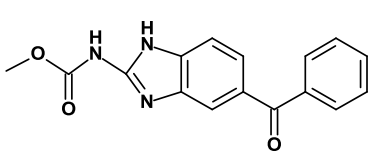

Nalidixic acid<smiles></smiles>

Pantoprazole

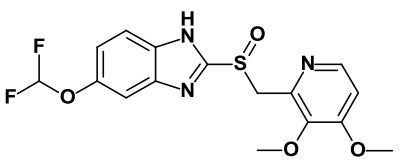

Sulfamethoxazole

Telmisartan
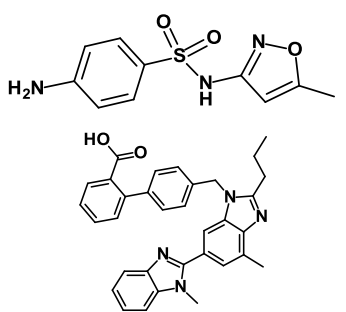
Table 2. Selected partition volumes of the shake-flask procedure.

\begin{tabular}{ll}
\hline $\log D_{\mathrm{o} / \mathrm{w}}$ range & $\boldsymbol{V}_{\mathrm{w}} / V_{\mathbf{o}}(\boldsymbol{V}$ in $\boldsymbol{\mu L})$ \\
\hline $\log D_{\mathrm{o} / \mathrm{w}}<-1$ & $200 / 5000,500 / 5000,500 / 500$ \\
$-1<\log D_{\mathrm{o} / \mathrm{w}}<0$ & $500 / 5000,500 / 500$ \\
$0<\log D_{\mathrm{o} / \mathrm{w}}<1.5$ & $500 / 5000,500 / 500,1000 / 100$ \\
$1.5<\log D_{\mathrm{o} / \mathrm{w}}<3.0$ & $1000 / 10,3000 / 10,5000 / 10$ \\
$3.0<\log D_{\mathrm{o} / \mathrm{w}}<3.5$ & $3000 / 10,5000 / 10$ \\
\hline
\end{tabular}


Table 3. CODESSA molecular descriptors used in the $\log P_{\mathrm{o} / \mathrm{w}}$ determination from chromatographic measurements.

\begin{tabular}{lcc}
\hline Compounds & HDCA-1/TMSA & HOMO-LUMO \\
\hline Benazepril & $3.64 \cdot 10^{-3}$ & 9.03 \\
Ciprofloxacin & $8.69 \cdot 10^{-3}$ & 8.26 \\
Esomeprazole & $3.46 \cdot 10^{-3}$ & 8.11 \\
Haloperidol & $3.47 \cdot 10^{-3}$ & 8.42 \\
Labetalol & $9.33 \cdot 10^{-3}$ & 9.17 \\
Mebendazole & $8.64 \cdot 10^{-3}$ & 8.35 \\
Nalidixic acid & $8.70 \cdot 10^{-3}$ & 8.47 \\
1-Naphthoic acid & $7.24 \cdot 10^{-3}$ & 8.16 \\
Pantoprazole & $5.75 \cdot 10^{-3}$ & 8.38 \\
Sulfamethoxazole & $4.99 \cdot 10^{-3}$ & 8.67 \\
Telmisartan & $3.25 \cdot 10^{-3}$ & 7.80 \\
\hline
\end{tabular}


Table 4. Comparison between the potentiometric reference acidity constants and the fitted ones from shake-flask (Eq. 4) and CHI (Eq. 5) vs. pH profiles.

\begin{tabular}{|c|c|c|c|c|c|}
\hline \multirow[b]{2}{*}{ Compound } & \multirow[b]{2}{*}{ Class $^{\mathrm{a}}$} & \multirow{2}{*}{$\begin{array}{c}\text { Potentiometric }^{\mathrm{b}} \\
\mathrm{p} K_{\mathrm{a} j}^{\prime \prime}\end{array}$} & \multirow{2}{*}{$\begin{array}{c}\text { Shake-flask }^{\mathrm{c}} \\
\mathbf{p} K_{\mathrm{a} j}^{\prime}\end{array}$} & \multicolumn{2}{|c|}{ CHI } \\
\hline & & & & $\mathbf{p} K_{\mathrm{a} j}^{\prime}$ & $s$ \\
\hline \multirow[t]{2}{*}{ Benazepril } & $\mathrm{H}_{2} \mathrm{X}^{+}$ & $3.35 \pm 0.25$ & $2.73 \pm 0.18$ & - & - \\
\hline & $\mathrm{HX}^{ \pm}$ & $5.43 \pm 0.02$ & $5.87 \pm 0.11$ & $4.86 \pm 0.08$ & $1.12 \pm 0.16$ \\
\hline \multirow[t]{2}{*}{ Ciprofloxacin } & $\mathrm{H}_{2} \mathrm{X}^{+}$ & $6.20 \pm 0.05$ & $4.08 \pm 0.50$ & - & - \\
\hline & $\mathrm{HX}^{ \pm}$ & $8.56 \pm 0.04$ & $8.85 \pm 0.17$ & $7.34 \pm 0.27$ & $0.49 \pm 0.18$ \\
\hline \multirow[t]{2}{*}{ Esomeprazole } & $\mathrm{H}_{2} \mathrm{X}^{+}$ & $4.60 \pm 0.08$ & $5.37 \pm 0.20$ & $3.46 \pm 0.96$ & $0.84 \pm 0.71$ \\
\hline & $\mathrm{HX}^{ \pm}$ & $8.86 \pm 0.04$ & $8.69 \pm 0.08$ & $10.13 \pm 0.23$ & $0.89 \pm 0.19$ \\
\hline \multirow[t]{2}{*}{ Haloperidol } & $\mathrm{H}_{2} \mathrm{X}^{+}$ & $8.54 \pm 0.09$ & $8.12 \pm 0.13$ & $8.15 \pm 0.09$ & $0.70 \pm 0.09$ \\
\hline & $\mathrm{HX}$ & $10.98 \pm 0.15$ & - & - & - \\
\hline \multirow[t]{2}{*}{ Labetalol } & $\mathrm{H}_{2} \mathrm{X}^{+}$ & $7.41 \pm 0.04$ & $7.59 \pm 0.32$ & $8.00 \pm 0.59$ & $0.72 \pm 0.46$ \\
\hline & $\mathrm{HX}^{ \pm}$ & $9.37 \pm 0.08$ & $9.32 \pm 0.23$ & $9.99 \pm 0.08$ & $1.82 \pm 0.94$ \\
\hline \multirow[t]{2}{*}{ Mebendazole } & $\mathrm{H}_{2} \mathrm{X}^{+}$ & $3.53 \pm 0.04$ & $3.59 \pm 0.16$ & - & - \\
\hline & $\mathrm{HX}$ & $9.88 \pm 0.06$ & $9.43 \pm 0.17$ & - & - \\
\hline Nalidixic acid & $\mathrm{HX}$ & $6.00 \pm 0.03$ & $6.41 \pm 0.11$ & $7.58 \pm 0.04$ & $1.04 \pm 0.11$ \\
\hline Pantoprazole & $\mathrm{HX}$ & $8.22 \pm 0.09$ & $8.38 \pm 0.06$ & $9.23 \pm 0.05$ & $1.03 \pm 0.13$ \\
\hline Sulfamethoxazole & $\mathrm{HX}$ & $5.65 \pm 0.03$ & $5.83 \pm 0.04$ & $6.47 \pm 0.09$ & $0.64 \pm 0.06$ \\
\hline \multirow[t]{3}{*}{ Telmisartan } & $\mathrm{H}_{3} \mathrm{X}^{+}$ & $3.01 \pm 0.09$ & $3.28 \pm 0.28$ & - & - \\
\hline & $\mathrm{H}_{2} \mathrm{X}^{ \pm}$ & $4.39 \pm 0.02$ & $4.60 \pm 0.44$ & $4.61 \pm 0.04$ & $0.92 \pm 0.05$ \\
\hline & $\mathrm{HX}^{-}$ & $6.02 \pm 0.03$ & $5.61 \pm 0.35$ & - & - \\
\hline
\end{tabular}

${ }^{\mathrm{a}}$ The acidic form of the compound is shown; ${ }^{\mathrm{b}} \mathrm{I}=0.15 \mathrm{M}(\mathrm{KCl}) ;{ }^{\mathrm{c}} \mathrm{I}=0.10 \mathrm{M}$ (several buffers). 
Table 5. Measured lipophilicity for the studied amphoteric and zwitterionic compounds.

\begin{tabular}{|c|c|c|c|c|c|}
\hline \multirow{2}{*}{ Compound } & \multirow[b]{2}{*}{ Class } & Shake-flask & \multirow{2}{*}{$\begin{array}{c}\text { Potenciometric } \\
\log \boldsymbol{P}_{\mathrm{o} / \mathrm{w}}(I=0.15 \mathrm{M})\end{array}$} & \multicolumn{2}{|c|}{ CHI method } \\
\hline & & $\log P_{\mathrm{o} / \mathrm{w}}(I=0.10 \mathrm{M})$ & & $\mathrm{CHI}_{\mathrm{MeCN}}$ & $\log P_{\mathrm{o} / \mathrm{w}}$ \\
\hline \multirow[t]{3}{*}{ Benazepril } & $\mathrm{H}_{2} \mathrm{X}^{+}$ & - & $0.07 \pm 0.10$ & - & - \\
\hline & $\mathrm{HX}^{ \pm}$ & $1.24 \pm 0.08$ & $1.38 \pm 0.01$ & $65.3 \pm 0.5$ & 2.07 \\
\hline & $\mathrm{X}^{-}$ & - & - & $52.2 \pm 0.2$ & - \\
\hline \multirow[t]{3}{*}{ Ciprofloxacin } & $\mathrm{H}_{2} \mathrm{X}^{+}$ & $-1.98 \pm 0.21$ & $-1.59 \pm 0.12$ & - & - \\
\hline & $\mathrm{HX}^{ \pm}$ & $-1.13 \pm 0.09$ & $-1.15 \pm 0.03$ & $31.5 \pm 0.7$ & 0.71 \\
\hline & $\mathrm{X}^{-}$ & - & - & $21.6 \pm 0.8$ & - \\
\hline \multirow[t]{3}{*}{ Esomeprazole } & $\mathrm{H}_{2} \mathrm{X}^{+}$ & - & - & $46.8 \pm 5.3$ & \\
\hline & $\mathrm{HX}^{ \pm}$ & $2.23 \pm 0.05$ & $2.17 \pm 0.01$ & $53.6 \pm 0.3$ & 1.50 \\
\hline & $\mathrm{X}^{-}$ & - & $0.39 \pm 0.04$ & $32.8 \pm 2.6$ & - \\
\hline \multirow[t]{2}{*}{ Haloperidol } & $\mathrm{H}_{2} \mathrm{X}^{+}$ & $1.53 \pm 0.04$ & $1.38 \pm 0.03$ & $61.8 \pm 0.7$ & - \\
\hline & HX & $3.52 \pm 0.09$ & $3.61 \pm 0.01$ & $89.3 \pm 0.9$ & 3.56 \\
\hline \multirow[t]{3}{*}{ Labetalol } & $\mathrm{H}_{2} \mathrm{X}^{+}$ & $0.17 \pm 0.08$ & $0.18 \pm 0.03$ & $45.6 \pm 0.4$ & - \\
\hline & $\mathrm{HX}^{ \pm}$ & $1.45 \pm 0.17$ & $1.37 \pm 0.02$ & $52.7 \pm 2.8$ & 1.89 \\
\hline & $\mathrm{X}^{-}$ & - & - & $39.6 \pm 0.7$ & - \\
\hline \multirow[t]{2}{*}{ Mebendazole } & $\mathrm{H}_{2} \mathrm{X}^{+}$ & - & $0.71 \pm 0.14$ & $61.6 \pm 0.4$ & - \\
\hline & HX & $3.09 \pm 0.07$ & $2.92 \pm 0.10$ & - & 2.47 \\
\hline \multirow[t]{2}{*}{ Nalidixic acid } & $\mathrm{HX}$ & $1.36 \pm 0.08$ & $1.48 \pm 0.02$ & $61.9 \pm 0.5$ & 2.48 \\
\hline & $\mathrm{X}^{-}$ & $-1.58 \pm 0.07$ & - & $27.5 \pm 0.4$ & - \\
\hline \multirow[t]{2}{*}{ Pantoprazole } & HX & $2.07 \pm 0.04$ & $1.84 \pm 0.01$ & $57.2 \pm 0.2$ & 1.91 \\
\hline & $\mathrm{X}^{-}$ & - & $-0.98 \pm 0.28$ & $39.6 \pm 0.7$ & - \\
\hline \multirow[t]{2}{*}{ Sulfamethoxazole } & $\mathrm{HX}$ & $0.86 \pm 0.02$ & $0.90 \pm 0.01$ & $47.9 \pm 0.7$ & 1.24 \\
\hline & $\mathrm{X}^{-}$ & - & - & $20.8 \pm 0.5$ & - \\
\hline \multirow[t]{3}{*}{ Telmisartan } & $\mathrm{H}_{3} \mathrm{X}^{+}$ & - & $1.45 \pm 0.29$ & - & - \\
\hline & $\mathrm{H}_{2} \mathrm{X}^{ \pm}$ & $4.18 \pm 0.29$ & $3.54 \pm 0.11$ & $90.3 \pm 2.4$ & 2.44 \\
\hline & $\mathrm{HX}^{-}$ & $1.46 \pm 0.09$ & $1.41 \pm 0.05$ & $52.7 \pm 0.4$ & - \\
\hline
\end{tabular}




\section{FIGURE CAPTIONS}

Figure 1. Maximum advisable mole fraction of neutral species for an amphoteric compound depending on the $\mathrm{p} K_{\mathrm{a}}$ distance between acidic and basic groups.

Figure 2. Lipophilicity profiles of some ordinary and zwitterionic ampholytes of pharmaceutical interest measured by different methods: a) (•) shake-flask with chromatographic UV detection; b) (solid lines) potentiometry; c) (匹) CHI; d) (dotted lines) estimated from ACD/Labs, Classic approach; e) (dashed lines) estimated from ACD/Labs, GALAS approach. For shake-flask and CHI, symbols represent experimental measurements and lines are the fittings to corresponding models (Eqs. (4) and (5)). The scale of the right $\mathrm{CHI}$ axis has been set to match that of the left $\log P_{\mathrm{o} / \mathrm{w}}$ axis by means of Eq. (3) and the molecular descriptors presented in Table 3. 


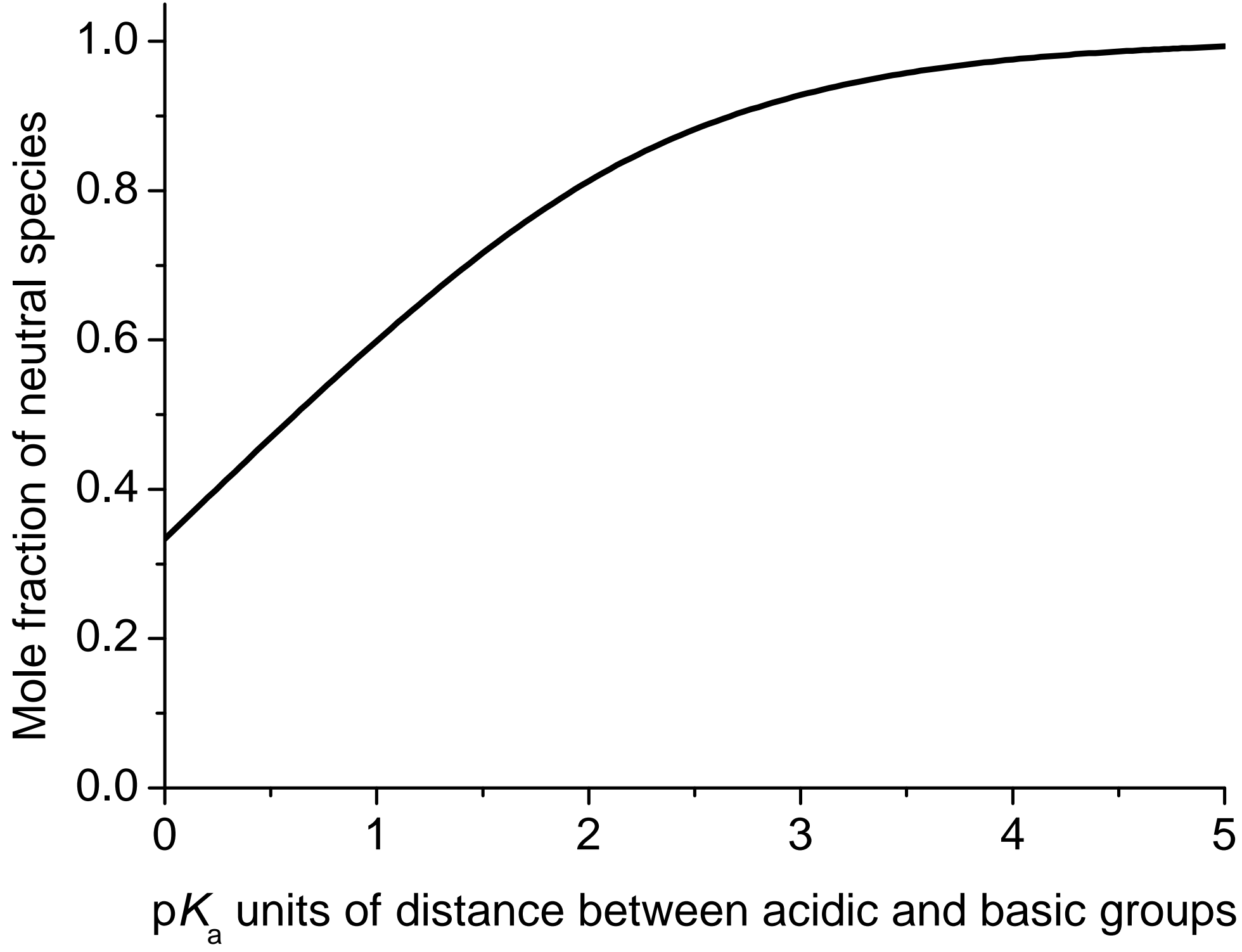


